\title{
Children living with disabilities are neglected in severe malnutrition protocols: a guideline review
}

\author{
Magdalena Engl (1) , ${ }^{1}$ Paul Binns, ${ }^{2}$ Indi $\operatorname{Trehan}_{,}{ }^{3}$ Natasha Lelijveld, ${ }^{4}$ Chloe Angood ${ }_{1}^{4}$ \\ Marie McGrath, ${ }^{4}$ Nora Groce, ${ }^{5}$ Marko Kerac (i) ${ }^{6,7}$
}

${ }^{1}$ Faculty of Infectious and Tropical Diseases, London School of Hygiene \& Tropical Medicine, London, UK ${ }^{2}$ Action Against Hunger, London, UK

${ }^{3}$ Departments of Pediatrics, Global Health, and Epidemiology, University of Washington, Seattle, Washington, USA

${ }^{4}$ Emergency Nutrition Network Kidlington, UK

${ }^{5}$ International Disability

Research Centre, Department of Epidemiology and Health

Care, University College London, London, UK

${ }^{6}$ Department of Population Health, London School of Hygiene and Tropical Medicine London, UK

Centre for Maternal,

Adolescent, Reproductive \& Child Health (MARCH), London School of Hygiene \& Tropical

Medicine, London, UK

\section{Correspondence to}

Dr Magdalena Engl, Faculty of Infectious and Tropical Diseases, London School of Hygiene \& Tropical Medicine, London, UK Magdalena.Engl1@alumni. Ishtm.ac.uk

Received 29 September 2021 Accepted 19 January 2022

\section{Check for updates}

(C) Author(s) (or their employer(s)) 2022. No commercial re-use. See rights and permissions. Published by BMJ.

To cite: Engl M, Binns $P$, Trehan I, et al. Arch Dis Child Epub ahead of print: [please include Day Month Year]. doi:10.1136/

archdischild-2021-323303

\begin{abstract}
Purpose Children living with disabilities are at high risk of malnutrition but have long been marginalised in malnutrition treatment programmes and research. The 2013 WHO guidelines for severe acute malnutrition (SAM) mention disability but do not contain specific details for treatment or support. This study assesses inclusion of children living with disabilities in national and international SAM guidelines.
\end{abstract}

Methods National and international SAM guidelines available in English, French, Spanish or Portuguese were sourced online and via direct enquiries. Regional guidelines or protocols subspecialising in a certain patient group (eg, people living with HIV) were excluded. Eight scoping key informant interviews were conducted with experts involved in guideline development to help understand possible barriers to formalising malnutrition guidance for children living with disabilities.

Results 71 malnutrition guidelines were reviewed (63 national, 8 international). National guidelines obtained covered the greater part of countries with a high burden of malnutrition. $85 \%$ of guidelines (60/71) mention disability, although mostly briefly. Only 4\% (3/71) had a specific section for children living with disabilities, while the remaining lacked guidance on consistently including them in programmes or practice. Only one guideline mentioned strategies to include children living with disabilities during a nutritional emergency. Most $(99 \%, 70 / 71)$ did not link to other disability-specific guidelines. Of the guidelines that included children living with disabilities, most only discussed disability in general terms despite the fact that different interventions are often needed for children with different conditions. Interviews pointed towards barriers related to medical complexity, resource constraints, epidemiology (eg, unrecognised burden), lack of evidence and difficulty of integration into existing guidelines.

Conclusion Children living with disabilities are under-recognised in most SAM guidelines. Where they are recognised, recommendations are very limited. Better evidence is urgently needed to identify and manage children living with disabilities in malnutrition programmes. More inclusion in the 2022 update of the WHO malnutrition guidelines could support this vulnerable group.

\section{INTRODUCTION}

Globally, some 291 million children and adolescents live with a disability, as shown in a recent analysis of the Global Burden of Disease Study 2017 data. ${ }^{1}$ It is also estimated that 47 million children aged under 5 years are suffering from wasting, ${ }^{2}$ and
What is already known on this topic?

- There is a strong association between disability and malnutrition, but children living with disabilities are often marginalised in malnutrition research and treatment programmes.

- The 2013 WHO guideline update for severe acute malnutrition (SAM) mentions disability but does not contain specific details on managing malnutrition in this vulnerable patient group.

- National and international malnutrition protocols are often based on WHO guidelines, and thus likely reflect this lack of disabilityspecific recommendations within the WHO guidelines.

\section{What this study adds?}

Many currently available national and international guidelines for SAM mention children living with disabilities, but few contain any specific management details.

- Scoping key informant interviews identified key challenges to providing recommendations for malnourished children living with disabilities, related to medical expertise, resources, epidemiology, evidence and guideline structure.

- The identified lack of specific guidance for this vulnerable group should prompt future guideline developers to aim for more inclusive protocols.

that a significant, but as yet unknown, number of children living with disabilities are among these millions of children. Disability and malnutrition interact in many ways: feeding problems related to anatomic or motor impairments, nutrient malabsorption or social exclusion are some of the ways in which underlying disability can increase the risk of malnutrition. ${ }^{3}$ A 2014 paper explains the pathways neurodisabilities can both cause and be caused by malnutrition. ${ }^{5}$ A 2018 systematic review found the pooled OR for undernutrition was three times higher for children living with disabilities, compared with children without disability (double for stunting and wasting, respectively). ${ }^{6}$ Children living with disabilities also have greater risk of adverse outcomes, including death, following treatment for severe acute malnutrition (SAM). 
Table 1 Search terms, contacts and online resources used

Online search terms used (and respective

translations to French, Spanish and Portuguese)

UNICEF regional/country offices contacted

Accessed online databases and document libraries
Combinations of 'Guideline(s)', 'Malnutrition', 'IMAM', 'CMAM', 'SAM', 'Integrated Management of Acute Malnutrition', 'Community (based) Management of Acute Malnutrition', 'Severe Acute Malnutrition', 'Acute', 'Wasting', 'Unternutrition', 'Nutrition', 'National', 'International'

UNICEF India, UNICEF East Africa, UNICEF West Africa, UNICEF South Asia, UNICEF Burundi, UNICEF New York

Document libraries of National Health Ministry homepages of countries listed in table 2:

Paho.org, who.int, espen.org, unhcr.org, unicef.org, nutritioncluster.net, validinternational.org, en-net.org, nowastedlives. org, acutemalnutrition.org, fantaproject,org, reliefweb.org, imtf.org, www.ennonline.net

CMAM, community-based management of acute malnutrition; SAM, severe acute malnutrition.

There is an imperative through the UN Convention on the Rights of Persons with Disabilities and the Sustainable Development Goals ${ }^{28}$ for international actors to commit to greater inclusion of persons living with disabilities in healthcare and in related sectors such as humanitarian practice initiatives. ${ }^{9-11}$ The 2013 update of the WHO SAM guidelines recognises disability as an underlying factor for malnutrition. However, disability is only briefly mentioned as a possible reason for referral for specialised care and there are no specific recommendations for this vulnerable patient group. The guideline does not include details on a proactive screening for disability, any specific feeding, nutrition or medical treatment recommendations, counselling advice for caregivers, prevention strategies or references to disabilityspecific guidelines (see table 4). ${ }^{12}$

The needs of children living with disabilities may differ from other children regarding more complex feeding problems, slower weight gain despite the same treatment and higher risk of not achieving nutritional recovery. Anthropometry can be more challenging: measuring weight-for-length may be difficult due to spastic contractures (and different target values may apply, eg, in children with growth restrictions), and mid-upper arm circumference accuracy may be influenced by differences in muscle mass or body composition ${ }^{13}$ changes.

There is an evidence gap around the identification and management of malnutrition in children living with disabilities, ${ }^{34}$ and disability can be an exclusion criterion in some studies on malnutrition. ${ }^{14}$ Greater inclusion of disability in nutrition research has been called for numerous times in the academic literature. ${ }^{4515}$ Still, there remain a number of 'unexplored opportunities for collaboration' between malnutrition and disability programmes, a need for more political and resource commitment, and a need for malnutrition policies and guidelines to contain detailed guidance specific to children living with disabilities leading to a higher visibility in front-line practice. ${ }^{15}$

This study aims to provide an overview of the current status of recommendations for children living with disabilities in national and international SAM guidelines, in light of the ongoing 2022 WHO malnutrition guideline update. These new guidelines will influence malnutrition care over the coming decade, and we hope this study will help highlight the need of more inclusivity.

\section{METHODS}

We aimed to identify the most current version of available national and international guidelines focusing on SAM in children aged 0-18 years. These were searched online using manual searching via common search engines, and using resource collections of national health ministries, malnutrition working groups and international organisations. Contacts of the coauthors, UNICEF regional office teams and respondents to a call posted on the Emergency Nutrition Network (ENN) global technical forum (https://en-net.org) helped identify additional guidelines. Table 1 provides details on guideline search strategies and sourcing.
The most current final or draft/interim version of national and international protocols were included. Protocols in English, French, Spanish or Portuguese were reviewed. Incomplete documents, regional guidelines or protocols subspecialising in a certain patient group (eg, people living with HIV) were excluded. After a full-text review of each guideline, relevant content on disability-specific information, clinical recommendations, monitoring and evaluation indicators, malnutrition prevention strategies and links to other pertinent guidelines were extracted into an electronic database.

Scoping key informant interviews were conducted to understand perceived barriers to formalising guidance specific to malnourished children living with disabilities. Based on previous work, we aimed for 10 participants to reach content saturation. ${ }^{16}$

Interview participants sought were experts on malnutrition involved in malnutrition guideline development in various roles and countries. They were contacted by purposive sampling via email using established professional networks, via an ENN forum call, and by snowball sampling.

Informants received an information sheet, signed a consent form and a previously piloted interview guide. They commented purely in a personal capacity, not representing any institutions or organisations.

Interviews were conducted by the lead author via an online video call and lasted approximately $45 \mathrm{~min}$. The interview was recorded, transcribed and anonymised, and participants were offered the transcripts to verify accuracy. Thematic analyses of the transcripts were performed following the steps outlined by Richie and Spencer. ${ }^{17}$

\section{RESULTS}

Seventy-one malnutrition guidelines were identified, of which $89 \%(63 / 71)$ were national guidelines from 56 countries (see table 2). For seven countries, more than one guideline was included as separate protocols existed, for example, for inpatient/outpatient treatment. National guidelines were distributed across the following UNICEF-designated regions: 32\% (20/63) from West and Central Africa, 29\% (18/63) from Eastern and Southern Africa, 14\% (9/63) from South Asia, 14\% (9/63) from East Asia and the Pacific, 6\% (4/63) from the Middle East and North Africa, and 5\% (3/63) from Latin America and the Caribbean. The final $11 \%(8 / 71)$ were international guidelines from one or more non-governmental organisations (NGOs). ${ }^{18-25}$ About 75\% (53/71) were published in 2013 and later.

While $85 \%$ of the guidelines (60/71) mention disability, most did so briefly. Only 4\% (3/71) have a dedicated section on children living with disabilities. With few exceptions, the extent of referencing disability in guidelines is limited to side notes. Table 4 shows content specific to children living with disabilities identified in the guidelines reviewed.

Cerebral palsy and cleft lip/palate were commonly mentioned disabilities. Very few guidelines highlighted proactive screening for disability $\left(3 / 60,5 \%^{26-28}\right)$ and almost none outlined 
Original research

\begin{tabular}{|c|c|c|c|c|}
\hline UNICEF region & Country or organisation & Year & Draft (interim) or final & Malnutrition guideline type \\
\hline \multirow[t]{6}{*}{ East Asia and the Pacific } & Cambodia (1) & 2017 & Final & $\begin{array}{l}\text { Outpatient (to be used in conjunction with } \\
\text { community+inpatient handbook) }\end{array}$ \\
\hline & Indonesia & 2019 & Final & IMAM \\
\hline & Lao PDR & 2018 & Final & IMAM \\
\hline & Philippines (1) & 2015 & Final & IMAM (in conjunction with MAM guideline) \\
\hline & Philippines (2) & 2016 & Final & IMAM (in conjunction with SAM guidelines) \\
\hline & Vietnam & 2016 & Final & CMAM \\
\hline \multirow[t]{5}{*}{ South Asia } & Afghanistan & 2018 & Final & IMAM \\
\hline & Bangladesh (1) & 2017 & Final & CMAM \\
\hline & Bangladesh (2) & 2017 & Final & inpatient \\
\hline & Pakistan & 2009 & Final & CMAM \\
\hline & Sri Lanka & 2007 & Final & SAM \\
\hline \multirow[t]{3}{*}{ Middle East and North Africa } & Lebanon & 2017 & Final & CMAM \\
\hline & Sudan & 2009 & Interim & CMAM \\
\hline & Yemen & 2013 & Interim & CMAM \\
\hline \multirow[t]{11}{*}{ Eastern and Southern Africa } & Angola & 2019 & Final & IMAM \\
\hline & Botswana & 2019 & Final & IMAM \\
\hline & Burundi & 2018 & Draft & IMAM \\
\hline & Comoros & 2013 & Final & IMAM \\
\hline & Eritrea & 2010 & Final & IMAM \\
\hline & Ethiopia & 2019 & Final & CMAM \\
\hline & South Sudan (1) & 2017 & Final & CMAM \\
\hline & South Sudan (2) & 2018 & Final & Inpatient \\
\hline & Tanzania & 2018 & Final & IMAM \\
\hline & Uganda & 2020 & Draft & IMAM \\
\hline & Zimbabwe & 2020 & Draft & IMAM \\
\hline \multirow[t]{19}{*}{ West and Central Africa } & Benin & 2011 & Final & CMAM \\
\hline & Burkina Faso & 2014 & Final & IMAM \\
\hline & Cameroon & 2013 & Final & IMAM \\
\hline & Central African Republic & 2014 & Final & IMAM \\
\hline & Chad & 2014 & Final & IMAM \\
\hline & Congo & 2015 & Final & IMAM \\
\hline & Democratic Republic Congo & 2016 & Final & IMAM \\
\hline & Gambia & 2013 & Final & IMAM \\
\hline & Ghana & 2010 & Interim & CMAM \\
\hline & Guinea & 2012 & Final & IMAM \\
\hline & Guinea-Bissau & 2013 & Final & IMAM \\
\hline & Liberia & 2012 & Final & IMAM \\
\hline & Mali & 2011 & Final & IMAM \\
\hline & Mauritania & 2011 & Final & IMAM \\
\hline & Niger & 2016 & Final & IMAM \\
\hline & Nigeria (1) & 2011 & Final & CMAM \\
\hline & Nigeria (2) & 2016 & Final & Inpatient \\
\hline & Senegal & 2013 & Final & CMAM \\
\hline & Sierra Leone & 2014 & Final & IMAM \\
\hline
\end{tabular}




\begin{tabular}{|c|c|c|c|c|}
\hline UNICEF region & Country or organisation & Year & Draft (interim) or final & Malnutrition guideline type \\
\hline \multirow[t]{3}{*}{ Latin America and Caribbean } & Haiti & 2010 & Final & CMAM \\
\hline & Honduras & 2004 & Final & Inpatient \\
\hline & Guatemala & 2009 & Final & $\begin{array}{l}\text { Inpatient (in Centro de Recuperación Nutricional=CRN, } \\
\text { not a hospital) }\end{array}$ \\
\hline \multirow[t]{8}{*}{ International guidelines } & $\begin{array}{l}\text { FANTA, ACF, WV, Valid, Concern, UNICEF, } \\
\text { FHI360, ALIMA, ENN, IRC, IMC, Save the Children }\end{array}$ & 2018 & Final & CMAM Training Guide \\
\hline & ACF International & 2011 & Final & IMAM \\
\hline & World Vision & 2017 & Final & CMAM project model \\
\hline & MSF-Intersectional & 2019 & Final & SAM (book chapter) \\
\hline & MSF OCG \& OCBA & 2015 & Draft & SAM \\
\hline & MSF-OCBA & 2014 & Final & Therapeutic feeding programme \\
\hline & MSF-B Niger & 2008 & Final & SAM \\
\hline & MSF & 2014 & Final & $\begin{array}{l}\text { Overall nutrition guidelines (SAM, MAM, nutrition } \\
\text { assessments and more) }\end{array}$ \\
\hline
\end{tabular}

CMAM, community-based management of acute malnutrition; SAM, severe acute malnutrition.

disability-specific feeding advice $\left(2 / 30,3 \%{ }^{26}{ }^{29}\right)$ or recommended a multidisciplinary treatment approach $\left(1 / 60,1,5 \%{ }^{26}\right)$.

Six out of 60 protocols (10\%) mentioned social and/or mental health support for children living with disabilities and their families:

- One out of 60 to establish a link with supporting families in nutritional emergency situations.

Table 3 Positive examples of guidelines with recommendations for children living with disabilities

\begin{tabular}{|c|c|}
\hline $\begin{array}{l}\text { Ethiopia } 2019 \\
\text { CMAM }^{28}\end{array}$ & $\begin{array}{l}\text { Specific chapter ('Vulnerable groups') } \\
\text { Recognises link between disability and malnutrition } \\
\text { Proactively screens for disability } \\
\text { 'Offer disability-specific feeding advice' (but does not specify) } \\
\text { Counselling on realistic outcome expectations } \\
\text { Regular home visits } \\
\text { Referral to support services }\end{array}$ \\
\hline $\begin{array}{l}\text { Lebanon } 2017 \\
\text { CMAM }^{26}\end{array}$ & $\begin{array}{l}\text { Specific chapter on children living with disabilities } \\
\text { Extensive information on cerebral palsy: team treatment } \\
\text { approaches (including gastroenterologists, speech therapists, } \\
\text { dieticians, nurses, psychologists), feeding advice, providing } \\
\text { daily micronutrient supplements } \\
\text { Link with support structures } \\
\text { Refers to guidance document on cerebral palsy }\end{array}$ \\
\hline $\begin{array}{l}\text { Malawi } 2016 \\
\text { CMAM }^{27}\end{array}$ & $\begin{array}{l}\text { Specific subheading (SAM in children living with disabilities) } \\
\text { Recognises link between disability and malnutrition } \\
\text { Proactively look for children living with disabilities } \\
\text { cerebral palsy) } \\
\text { Counsel and advise parents about disability } \\
\text { 'Offer disability-specific feeding and treatment' } \\
\text { 'Provide realistic outcome expectations' } \\
\text { Refer to appropriate services }\end{array}$ \\
\hline
\end{tabular}

$\begin{array}{ll}\begin{array}{l}\text { Timor-Leste } \\ 2016 \text { Specific }\end{array} & \begin{array}{l}\text { Lists children living with disabilities as vulnerable group in } \\ \text { emergencies (but notes that prevalence of malnutrition in this } \\ \text { Nutrition }\end{array} \\ \text { Intervention } & \begin{array}{l}\text { group is unknown) } \\ \text { In emergencies: give general ration, organise food distribution } \\ \text { Package }\end{array} \\ \text { Guidelines }^{29} & \begin{array}{l}\text { adapted to their needs, link disabled people with supporting } \\ \text { families for joint preparation of meals, health/nutrition/ } \\ \text { hygiene education, gives feeding advice for children with oral } \\ \text { malformations } \\ \text { Proactively screen, specifies to 'also look for developmental } \\ \text { delay' }\end{array}\end{array}$

CLWDs, children living with disabilities ; CMAM, community-based management of acute malnutrition; RUTF, ready-to-use therapeutic food.
- One out of 60 to prioritise children living with disabilities for psychosocial support.

- One out of 60 discussed informing caretakers on realistic outcome expectations (eg, slower weight gain).

- One out of 60 recommended home visits for children living with disabilities.

- Two out of 60 encouraged to provide counselling on the nutritional needs of children living with disabilities.

- Three out of 60 to 'refer to appropriate support services' (no specifics).

Very few guidelines $(3 / 60,5 \%)$ include any Monitoring and Evaluation (M\&E) indicators specific to disability.

There were four positive examples of more inclusive guidelines that are highlighted in table 3.

\section{Perceived barriers to formalising recommendations}

Eight malnutrition experts (three female, five male) were recruited for the scoping interviews (zero participation refusals). Participants worked as clinicians, academics, policy makers and/or independent consultants; all had been involved in the development of malnutrition guidelines. Regarding perceived barriers to including children living with disabilities in malnutrition guidelines, five main themes emerged: Medical expertise, Resources, Epidemiology, Evidence, and Guideline Structure. Within medical expertise, subthemes identified were available diagnostics and staff knowledge.

Regarding medical expertise, the perceived medical complexity, wide range of disabilities and difficulty in developing a guideline that fits all were brought up by several experts $(5 / 8)$ as a key challenge. As one participant said, "That's where the problem starts to get really complicated (...). Is it mental or is it physical? (...) what is it that's causing the disability? What are the functional outcomes $(\ldots)$ ?"”.

Several informants $(5 / 8)$ mentioned a weak evidence base for recommendations, including around the correct use of anthropometrics (eg, special growth charts for children living with disabilities). One participant said, "I have looked hard enough for it. But (...) I found very little...”. Another mentioned the difficulties of designing studies to include children living with disabilities as the various disabilities make for a complex and heterogeneous study population, with arising data difficult to interpret.

Three participants brought up possible resource constraints, one clinician pointing out that "They have a much harder time recovering (...), so then they get treated again (...)And they're in 
the program for months (...) So, it become very expensive to the program (...)".

Epidemiology was discussed by four informants, for example, noting that children living with disabilities may not be officially registered (and thus the prevalence remaining unrecognised).

Two participants commented on guideline structures, one saying that recommendations on children living with disabilities may be hard to fit into a space-constrained document. Another discussed the benefits and drawbacks of the creation of many separate guidelines (eg, for malnutrition in people living with HIV, in the elderly, in children living with disabilities).

\section{DISCUSSION}

This study shows that children living with disabilities are still largely invisible in most national and international malnutrition guidelines. Due to the wide range of disabilities, this can be a complex topic, as some children living with different types of disability need tailored approaches. An important concept within the move towards more inclusivity is the 'twin-track approach', combining mainstreaming (addressing inequalities in all areas of programmes, ensuring equal access to basic needs and interventions) with targeted and individualised support of persons with disabilities. $^{30}$

A first step in making children living with disabilities visible in guidelines and front-line practice is recommending active screening for disability during case finding and admission to malnutrition treatment programmes, be that inpatient or community-based. Recent work suggests that formal screening tools may help with this: many types of disabilities, especially those that are less severe or less obvious are missed via routine clinical examination alone. ${ }^{7}$ Some disabilities can be challenging to diagnose clinically, and malnutrition treatment failure, relapse cases or malnutrition in older children should prompt investigations towards disability. Technical difficulties in measuring the height or length of children with postural impairments (eg, muscle contractures in cerebral palsy) also need to be addressed, for example, via alternative indicators. ${ }^{31}$ Not including specific indicators for children living with disabilities during M\&E processes perpetuates their invisibility, increasing the likelihood that the scale of the problem will remain difficult to recognise. A first step could simply mean including an indicator in tally sheets of malnutrition programmes to record all children admitted with any disability (ensuring no double-counting in the process), and to record their types of discharges to show the scale of patient load and outcomes. In a future step, differentiations between types of disabilities could be made, to allow more tailored support of prevalent disabilities.

Reiterating the human rights imperative of providing every child with the chance to survive and thrive, there are a variety of opportunities for increasing the chances of children living with disabilities to receive optimal care, ranging from awareness of risk and the early identification to appropriate treatment, more intensive follow-up, and linking with social, economic and mental health support for the child and family. A small but increasing number of resources exist to support feeding and nutrition in children with disabilities, ranging from models for social support to more clinical guidance or to specific feeding support, for example, for children with cerebral palsy. ${ }^{32-40}$

The evidence base relating to malnutrition in children living with disabilities is sparse and needs to be strengthened by acknowledging this as a research priority. While it is good that the $2013 \mathrm{WHO}$ SAM guideline update mentions disability, details in the guidelines are very limited and so it is arguably unsurprising that 8 years
Table 4 Including children living with disabilities for future severe malnutrition guidelines: suggested areas for inclusion

\begin{tabular}{|c|c|c|}
\hline Suggested areas for inclusion & $\begin{array}{l}\text { Included in } \\
2013 \text { WHO SAM } \\
\text { guideline update }\end{array}$ & $\begin{array}{l}\text { Included in x number } \\
\text { of guidelines analysed } \\
\text { for this study }\end{array}$ \\
\hline Link of disability with malnutrition & Briefly & $\begin{array}{l}\text { Briefly acknowledge link: } \\
6 / 60(10 \%) \\
\text { Acknowledge disability } \\
\text { as a possible reason for } \\
\text { malnutrition treatment } \\
\text { failure or non-response: } \\
39 / 60(65 \%)\end{array}$ \\
\hline $\begin{array}{l}\text { Proactive screening for disability and } \\
\text { developmental delay }\end{array}$ & No & $\begin{array}{l}\text { Proactively screen: } \\
3 / 60(5 \%) \\
\text { Disability yes/no on } \\
\text { physical assessment } \\
\text { form: } \\
42 / 60(70 \%)\end{array}$ \\
\hline $\begin{array}{l}\text { Multidisciplinary team management } \\
\text { (as available speech and language } \\
\text { therapy, dieticians, physiotherapists, } \\
\text { occupational therapy, psychologists, } \\
\text { nurses, medical team including } \\
\text { neurology and gastroenterology, } \\
\text { social services) }\end{array}$ & No & $\begin{array}{l}\text { Outlining } \\
\text { multidisciplinary } \\
\text { approach: } 1 / 60 \\
(1.5 \% 26) \\
\text { Suggesting disability as } \\
\text { a reason for inpatient } \\
\text { treatment: } 18 / 60(30 \%)\end{array}$ \\
\hline $\begin{array}{l}\text { Disability-specific feeding advice, } \\
\text { medical advice (as context- } \\
\text { appropriate, possibly including } \\
\text { advanced feeding techniques, eg, } \\
\text { percutaneous gastrostomy) }\end{array}$ & No & $\begin{array}{l}\text { Specific feeding } \\
\text { advice: } \\
2 / 60 \text { ( } 3 \% 2629) \\
\text { Noting disability (eg, } \\
\text { cleft lip/palate) as } \\
\text { possible indication for } \\
\text { nasogastric tube feeding: } \\
43 / 60(72 \%)\end{array}$ \\
\hline $\begin{array}{l}\text { Continued support within the home } \\
\text { (eg, home visits, home adaptations) }\end{array}$ & No & $1 / 60\left(1.5 \%{ }^{28}\right)$ \\
\hline Referral mechanisms & No & $\begin{array}{l}18 / 30(30 \%) \text {-mostly } \\
\text { unspecific ('referral to } \\
\text { specialists') }\end{array}$ \\
\hline $\begin{array}{l}\text { Counselling and advice for } \\
\text { caregivers (including management of } \\
\text { expectations) }\end{array}$ & No & $4 / 60(7 \%)$ \\
\hline Monitoring and evaluation & No & $3 / 60(5 \%)$ \\
\hline $\begin{array}{l}\text { Consideration of children living with } \\
\text { disabilities in nutrition emergencies, } \\
\text { malnutrition prevention strategies }\end{array}$ & No & $1 / 60(1.5 \% 29)$ \\
\hline $\begin{array}{l}\text { Linking to local and context-specific } \\
\text { organisations/groups providing } \\
\text { additional support }\end{array}$ & No & $\begin{array}{l}3 / 60(5 \%) \text { : 'refer to } \\
\text { appropriate support } \\
\text { services' (few specifics) }\end{array}$ \\
\hline Linking to other relevant guidance & No & $\begin{array}{l}1 / 60\left(1.5 \%{ }^{26} \text { linking to }\right. \\
\text { a cerebral palsy feeding } \\
\left.\text { and nutrition review }{ }^{42}\right)\end{array}$ \\
\hline
\end{tabular}

SAM, severe acute malnutrition.

on, there is a continuing lack of tailored recommendations in the protocols reviewed in this study. Many national and international malnutrition guidelines are modelled on the WHO guidelines, and several are based on template guidelines. In the case of the protocols reviewed here, several were derived from the 2011 IMAM Generic Protocol developed by Golden and Grellety. ${ }^{41}$ Changes in these widely used templates towards more inclusion of children living with disabilities, or the creation of new guides to mainstream disability into all aspects of CMAM guidelines could have a significant impact on protocols globally. The upcoming 2022 update of the $\mathrm{WHO}$ wasting guidelines is a good opportunity to create more inclusive guidelines. It offers the opportunity to include disability in the search strategy of the systematic reviews commissioned for evidence collection. Guidelines may consider a distinct section for 
the treatment of SAM in children living with disabilities to highlight their vulnerability and respond to their needs. Another option may be their integration all throughout updated guidelines, as this may still further their inclusion if viewed as an integral part of all treatment programmes rather than a separated patient group. However, the evidence base for such guidance remains sparse.

Recommendations need to go beyond mentioning disability as a side note. There is a need to be specific and detailed to allow health workers without extensive experience in disability to provide optimal care. Stating 'provide feeding as adequate for the respective condition' is insufficient without specifying what this would mean for children with different types of disability; there needs to be more detailed 'how-to', step-by-step guidance. In order to create this kind of guidance, disability needs to be included in the systematic evidence gathering for malnutrition guideline development and should be highlighted as a research priority.

Integrating disability into $\mathrm{M} \& \mathrm{E}$ and nutrition and coverage surveys is another vital step to ensure the actual caseload of children living with disabilities is more visible. National guidelines would benefit from including country-specific information on available disability support services, calling on the expertise of both national and international advocates and experts. If the scope of the guidelines does not allow for this level of detail, a link to other guidance should be established. The option of entirely separate country-specific protocol documents for malnutrition in children living with disabilities (similar to existing stand-alone guidelines for malnutrition in people living with HIV), a related template guideline and/or a guide to mainstream disability into national CMAM protocols could be discussed, and may be appropriate for some countries, although the merits and drawbacks of these approaches must be considered on a country-by-country basis.

Table 4 shows initial suggestions of areas of inclusion for more inclusive guidance on managing malnutrition in children living with disabilities, to be further developed and built on.

This study has several limitations. First, even if a guideline contains specific recommendations for children living with disabilities, this does not necessarily translate into practical, effective implementation, which may vary in different settings. Second, not all existing guidelines could be identified for inclusion in this study. Nevertheless, the 63 national guidelines included cover the greater part of countries with a high burden of malnutrition, thus, we believe, valid conclusions can still be reached. Finally, interviews were scoping interviews to help with initial understanding of the issues. Future work would include a wider range of key informants.

In conclusion, children living with disabilities are still largely marginalised in malnutrition guidelines intended for all children. Although recognition is an important first step, much work needs to be done to expand guidance on the specifics of their identification and management. We hope our findings can help raise awareness of the need for a commitment towards greater visibility and inclusion of malnourished children living with disabilities.

Twitter Marko Kerac@GlobalHealthNut

Acknowledgements We sincerely thank everyone helping to source the guidelines, and all the interviewees for taking time to share their insights with us.

Contributors MK and ME had the initial idea for this paper, and act as guarantors for this study. Other authors contributed to a different earlier version of the guideline review project. MK led the design process. ME did the literature and guideline review. Interviews were conducted, transcribed and analysed by ME. The first draft of the paper was written by ME, which was reviewed and revised by all coauthors.
Funding ME (part-funded), CA, NL and MM were funded by Irish Aid and the Eleanor Crook Foundation. MK also acknowledges the Eleanor Crook Foundation for funding support.

Competing interests IT acts as an Associate Editor at the Archives of Disease in Childhood, but was not involved in the peer review of this publication.

Patient consent for publication Not applicable.

Ethics approval This study was approved by the London School of Tropical Medicine (LSHTM) ethics committee (reference number 21844). Participants gave informed consent to participate in the study before taking part.

Provenance and peer review Not commissioned; externally peer reviewed

Data are available upon request.

\section{ORCID iDs}

Magdalena Engl http://orcid.org/0000-0002-7378-7495

Marko Kerac http://orcid.org/0000-0002-3745-7317

\section{REFERENCES}

1 Olusanya BO, Wright SM, Nair MKC, et al. Global burden of childhood epilepsy, intellectual disability, and sensory impairments. Pediatrics 2020;146. doi:10.1542/ peds.2019-2623. [Epub ahead of print: 1706 2020].

2 United Nations. The sustainable development goals report 2020, 2020. Available: https://unstats.un.org/sdgs/report/2020/

3 Kuper H, Nyapera V, Evans J, et al. Malnutrition and childhood disability in Turkana, Kenya: results from a case-control study. PLoS One 2015;10:e0144926.

4 Groce NE, Kerac M, Farkas A, et al. Inclusive nutrition for children and adults with disabilities. Lancet Glob Health 2013;1:e180-1.

5 Kerac M, Postels DG, Mallewa M, et al. The interaction of malnutrition and neurologic disability in Africa. Semin Pediatr Neurol 2014;21:42-9.

6 Hume-Nixon M, Kuper $\mathrm{H}$. The association between malnutrition and childhood disability in low- and middle- income countries: systematic review and meta-analysis of observational studies. Trop Med Int Health 2018;23:1158-75.

7 Lelijveld N, Groce N, Patel S, et al. Long-term outcomes for children with disability and severe acute malnutrition in Malawi. BMJ Glob Health 2020:5:e002613.

8 The United Nations. Convention on the rights of persons with disabilities 2006.

9 Akerkar S, Bhardwaj R. Good practice guide: embedding inclusion of older people and people with disabilities in humanitarian policy and practice. Age and Disability Consortium (ADCAP) 2018:1-160.

10 UNICEF. Core Committments for children in humanitarian action 2020. Available: https://www.unicef.org/emergencies/core-commitments-children

11 Stough LM, Kang D. The Sendai framework for disaster risk reduction and persons with disabilities. Int J Disaster Risk Sci 2015;6:140-9.

12 World Health Organization. Updates on the management of severe acute malnutrition in infants and children. Geneva: World Health Organization, 2013

13 McDonald CM, Abresch-Meyer AL, Nelson MD, et al. Body mass index and body composition measures by dual X-ray absorptiometry in patients aged 10 to 21 years with spinal cord injury. J Spinal Cord Med 2007:30 Suppl 1:S97-104.

14 Lelijveld N, Kerac M. A holistic approach to malnutrition follow-up care. J Public Health Emerg 2017;1:44.

15 Groce N, Challenger E, Berman-Bieler R, et al. Malnutrition and disability: unexplored opportunities for collaboration. Paediatr Int Child Health 2014:34:308-14.

16 Read S, McGrath M. Community management of uncomplicated malnourished infants under six months old: barriers to national policy change. Field Exchange 57 2018;27.

17 Ritchie J, Spencer L. Qualitative data analysis for applied policy research. The qualitative researcher's companion 2002:2002:305-29.

18 Médecins sans Frontières. Clinical guidelines 2020. Available: medicalguidelines.msf. org

19 Médecins sans Frontières. Nutrition guidelines 2014. Available: https://bibop.ocg.msf. org/docs/16/L016NUTM01E-P_Nutrition-2014.pdf

20 Médecins sans Frontières OCG \& OCBA. Protocols for Management of Nutritional Support in Children with Severe Acute Malnutrition. Internal Guideline - Pilot Version 2015. Available: https://bibop.ocg.msf.org/docs/16/L016NUTM19E-E_PEDNUT-NutEN_2015.pdf

21 Médecins sans Frontières OCB Niger. Protocole Nutritionnel - Médical Nouveau-nés et nourrissons 2008.

22 Médecins sans Frontières OCBA. Therapeutic feeding programme - nutritional and medical protocol. All age groups 2014.

23 ACF International. Guidelines for the integrated management of severe acute malnutrition: in- and out-patient treatment 2011. Available: https://www. actionagainsthunger.org/publication/guildines-integrated-management-severe-acutemalnutrition-and-out-patient-treatment

24 FANTA III UNICEF Concern. Training guide for community-based management of acute malnutrition (CMAM), 2018. Available: https://www.fantaproject.org/focus-areas/ nutrition-emergencies-mam/cmam-training

25 World Vision. Community-Based Management of Acute Malnutrition (CMAM) Project Model, 2017. Available: https://www.wvi.org/nutrition/project-models/cmam 
26 Republic of Lebanon Ministry of Public Health. Management of Acute Malnutrition National Guidelines 2017

27 Government of Malawi Ministry of Health. Guidelines for community-based management of acute malnutrition 2016. Available: https://www.fantaproject.org/ sites/default/files/resources/Malawi-CMAM-Guidelines-Dec2016.pdf

28 Government of Ethiopia Federal Ministry of Health. National guideline for the management of acute malnutrition in Ethiopia 2019.

29 Ministry of Health Timor-Leste. Specific nutrition intervention package (snip) guidelines 2016

30 DFID. Disability, poverty and development, 2000. Available: https://hpod.law.harvard. edu/pdf/Disability-poverty-and-development.pdf

31 Yousafzai AK, Filteau SM, Wirz SL, et al. Comparison of armspan, arm length and tibia length as predictors of actual height of disabled and nondisabled children in Dharavi, Mumbai, India. Eur J Clin Nutr 2003;57:1230-4.

32 Zuurmond M, O'Banion D, Gladstone M, et al. Evaluating the impact of a communitybased parent training programme for children with cerebral palsy in Ghana. PLOS One 2018;13:e0202096.

33 Holt International. Holt International's Feeding and Positioning Manual: Guidelines for Working with Babies and Children, 2019. Available: https://www.holtinternational. org/about/child-nutrition/feeding-and-positioning-manual/
34 MCAI (Maternal \& Childhealth Advocacy International). International Maternal \& Child Health Care: A practical manual for hospitals worldwide. Raddliffe Publishing Ltd, 2014.

35 SPOON. Count Me In, 2019. Available: http://www.spoonfoundation.org/what-we-do/ our-approach/count-me-in/;

36 Werner D. Disabled village children: the Hesperian Foundation, 1987. Available: https://www.dinf.ne.jp/doc/english/global/david/dwe002/dwe00201.html\#index

37 LSHTM, ICED, CBM. Getting to know cerebral palsy (module 0), 2013. Available: https://www.lshtm.ac.uk/media/24276

38 LSHTM, ICED, CBM. Getting to know cerebral palsy - module 6 (feeding your child), 2013. Available: https://www.Ishtm.ac.uk/media/24306

39 Banerjee R, Kundu M, Arundhuti B. Feeding for the child with cerebral palsy Indian Institute of cerebral palsy: Indian Institute of cerebral palsy, 1995. Available: https:// asksource.info/pdf/A933_feedingthechild_1995.pdf

40 CBM. Humanitarian Hands-On Tool (HHOT). Available: https://hhot.cbm.org/en/

41 Golden M, Grellety Y. Golden MH Grellety Y, integrated management of acute malnutrition (IMAM) generic protocol ENGLISH version 6.6.2, 2011. Available: https://www.researchgate.net/publication/292131715_Golden_MH_Grellety_ Y_Integrated_Management_of_Acute_Malnutrition_IMAM_Generic_Protocol_ ENGLISH_version_662

42 Ferluga ED, Archer KR, Sathe NA. Interventions for feeding and nutrition in cerebral palsy. Comparative Effectiveness Reviews 2013;94. 